\title{
Reversal of rivaroxaban anticoagulant effect by prothrombin complex concentrates: which dose is sufficient to restore normal thrombin generation?
}

\author{
Lorine Giffard-Quillon ${ }^{1}$, Helene Desmurs-Clavel ${ }^{1,2}$, Claire Grange ${ }^{1,3}$, Yohann Jourdy ${ }^{4}$ and Yesim Dargaud ${ }^{1,4,5^{*}}$ (D)
}

\begin{abstract}
Rivaroxaban has the most available data to support the use of prothrombin complex concentrates (PCC) as a reversal agent. However, PCC might increase the incidence of thrombotic events by shifting the haemostatic balance towards hypercoagulability. We assessed the in vitro efficacy and safety of three 4-factor PCCs for reversing rivaroxaban anticoagulant effect. Our in vitro finding indicates that 4-factor PCCs at the dose of $25 \mathrm{U.kg}^{-1}$ may be sufficient to reverse rivaroxaban anticoagulant effect.
\end{abstract}

Rivaroxaban is a direct oral activated factor $\mathrm{X}$ inhibitor. One of the main advantages of direct acting oral anticoagulants (DOAC) is the lower incidence of major bleeding complications, with $50 \%$ lower chances of intracranial haemorrhages compared with warfarin. However, DOAC may increase gastrointestinal bleeding and have been associated with heavy menstrual bleeding $[1,2]$. Therefore, neutralization of the anticoagulant effect is a key step in the management of DOAC-related major bleeding complications. Andexanet- $\alpha$ is a catalytically inactive recombinant factor Xa protein that binds to both factor Xa inhibitors and native factor Xa (1:1 ratio), thus acting as competitive inhibitor. However, andexanet- $\alpha$ has been only conditionally approved by the European Medicines Agency because of the observed high incidence of thromboembolic events [3]. International guidelines recommend the administration of prothrombin complex concentrates (PCCs) in case of life-

\footnotetext{
* Correspondence: ydargaud@univ-lyon1.fr

'GEMMAT Groupe d'Etude Multidisciplinaire en Maladies Thrombotiques, Lyon, France

${ }^{4}$ Laboratoire d'Hematologie, Groupement Hospitalier Est, Hospices Civils de Lyon, Lyon, France

Full list of author information is available at the end of the article
}

threatening bleeding caused by DOACs, in the absence of specific reversal agents $[3,4]$. The initial dose of 50 U. $\mathrm{kg}^{1}$ is effective for achieving haemostasis and restoring thrombin generation. However, different groups have recently reported that PCCs at $25{\mathrm{U} . \mathrm{kg}^{-1}}^{-1}$ provides effective anticoagulant reversal in patients with major bleeding complications associated with factor Xa inhibitors $[5,6]$. Moreover, some experts suggested that activated PCC (APCC, FEIBA@, Takeda, Japan) could be an effective strategy to improve haemostasis in DOAC-related major bleeding events $[7,8]$. Although clinical guidelines recommend PCCs for the treatment of DOAC-associated bleeding events [9], some authors suggested that PCCs may not be effective in this situation [10]. In the present study, we assessed the in vitro efficacy and safety of three 4-factor PCCs that contain the human coagulation factors II, VII, IX and X and are commercially available in France for reversing rivaroxaban anticoagulant effect.

After informed consent, blood samples of 40 patients who were treated with rivaroxaban $(20 \mathrm{mg}$ per day) after a venous thromboembolism were collected during a routine visit, at random times relative to the drug administration time. Rivaroxaban levels were measured 
using an amidolytic anti-Xa assay with drug-specific calibrators (HemosIL Liquid anti-Xa assay, Werfen, Le Pré-Saint Gervais, France) and a Werfen ACL top 750 analyser (Werfen, Le Pré-Saint Gervais, France). Rivaroxaban levels were high in four patients (200-300 ng. $\left.\mathrm{mL}^{-1}\right)$, within the usual therapeutic range (31-200 ng. $\left.\mathrm{mL}^{-1}\right)$ in twenty patients, and low in eleven patients $\left(25-30 \mathrm{ng} \cdot \mathrm{mL}^{-1}\right)$. Five plasma samples were excluded from the study because of undetectable rivaroxaban levels.

PCC reversal ability was tested using the thrombin generation assay (TGA) because the routine coagulation techniques to evaluate haemostasis in clinical laboratories are not sensitive enough to detect hypercoagulable and mild hypocoagulable states. TGA is a global haemostasis test that assesses the balance between procoagulant and anticoagulant proteins and might meet these requirements. Moreover, several groups previously reported that TGA can better reflect the bleeding or thrombosis risk of each individual patient compared with other routine coagulation assays based on activated partial thromboplastin time or prothrombin time [11]. For this assay, blood was collected in BD Vacutainer ${ }^{\circ}$ tubes with $3.2 \%$ buffered sodium citrate solution and without corn trypsin inhibitor. For thrombin generation measurement, platelet-poor plasma samples were prepared as previously described for TGA [12], and spiked with three different PCCs available in France Kanokad $^{\circ}$ (LFB, Courtaboeuf, France), Confidex ${ }^{\circ}$ (CSL Behring, Marburg, Germany) and Octaplex ${ }^{\circ}$ (Octapharma, Lachen, Switzerland)], to obtain different final concentrations $\left(0-0.375-0.625-0.875\right.$ and $\left.1.25 \mathrm{U} \cdot \mathrm{mL}^{-1}\right)$ that correspond to the clinical doses of $0-15-25-35$ and $50 \mathrm{U} \cdot \mathrm{kg}^{-1}$, respectively. Thrombin generation was measured using the Calibrated Automated Thrombin Generation Assay (Stago, Asnières, France) and the CAT PPP-reagent (Stago, Asnières, France), as previously described [12].

The presence of rivaroxaban in plasma modifies the appearance of the thrombin generation curve (i.e. "camel-back" shaped curve) [13], with delayed and reduced peak height and low endogenous thrombin potential (ETP). In our experimental conditions, the anti-Xa effect of rivaroxaban was more obvious on the thrombin peak height than on ETP (Fig. 1A). Therefore, the peak height was used as the TGA main parameter to assess PCC reversal effect. In the absence of PCCs, the peak height of samples from treated patients was $113 \pm$ $53 \mathrm{nM}$ (mean $\pm \mathrm{SD}$ ). Overall, rivaroxaban levels were negatively correlated with thrombin peak height $(\mathrm{r}=-$ 0.6241 , CI 95\% $=-0.83-0.26 ; P=0.0019$, Spearman correlation test). Peak height values were lower in patients with high rivaroxaban levels.
In spiked samples, Kanokad ${ }^{\circ}$ and Confidex ${ }^{\circ}$ similarly increased thrombin peak height $(p>0.05$; Mann Whitney test) at all tested concentrations. Thrombin peak height values and lag time were normalized with Kanokad $^{\circ} 25 \mathrm{U.kg}^{-1}(221 \pm 92 \mathrm{nM})$ and Confidex ${ }^{\circ} 25$ $\mathrm{U}_{\mathrm{kg}}{ }^{-1}(201 \pm 94 \mathrm{nM})$ and remained in the normal range (Fig. 1A). Normal thrombin peak height values were previously determined in our laboratory in 100 healthy individuals without history of bleeding or thrombosis and who were not taking any medication that might interfere with coagulation. Thrombin generation measurement in these control samples in identical experimental conditions indicated that the normal peak height range was $280 \pm 102$ (mean $\pm 2 \mathrm{SD}$ ) $\mathrm{nM}$. The thrombin peak and ETP values obtained in patient samples spiked with $\mathrm{Kanokad}^{\circ}$ and Confidex ${ }^{\circ}\left(25\right.$ and $50{\mathrm{U} . \mathrm{kg}^{-1}}^{-1}$ ) were not significantly different $(p>0.05$; Mann Whitney $\mathrm{U}$ test) (Fig. 1B). Conversely, with lower dose of Kanokad ${ }^{\circ}$ and Confidex ${ }^{\circ}\left(15 \mathrm{U}^{\mathrm{kg}}{ }^{-1}\right)$, thrombin peak and ETP values were significantly lower than in controls $(p=0.03$ and 0.04 respectively; Mann Whitney $U$ test). It is worth noting that in samples with low plasma rivaroxaban concentration, thrombin peak height reached values above the normal range after spiking with PCCs $50 \mathrm{U} \cdot \mathrm{kg}^{-1}$ (Fig. 1C). Quantification of heparin concentration in the PCC preparations showed that it was much higher in Octaplex $^{\bullet}(0.3$ anti-Xa units $/ \mathrm{mL})$ than in the other PCCs $(<0.1$ anti-Xa units/mL). Consequently, thrombin generation peak and the area under the thrombin generation curve were inhibited in a dose-dependent manner in the presence of Octaplex ${ }^{\circ}$, and the in vitro results could not be reliably interpreted (Fig. 1).

PCCs are easy to obtain and can effectively reverse DOAC activity. They efficiently improve the coagulation parameters and decrease blood loss. However, dose recommendations are difficult due to lack of data, and the currently suggested dose for 4-factor PCCs is 25-50 $\mathrm{U} / \mathrm{kg}$ [14]. On the basis of their potential thromboembolic risk and cost, it appears safe to use the minimum effective dose in patients with DOAC-related haemorrhages. Our in vitro results, obtained with two different 4-factor PCCs $\left(\mathrm{Kanokad}^{\circ}\right.$ and $\left.\mathrm{Confidex}^{\circ}\right)$ indicated that 25 and $50 \mathrm{U} \cdot \mathrm{kg}^{-1}$ led to an effective thrombin generation. However, they did not completely normalize all TGA parameters, particularly in samples with high concentrations of rivaroxaban. Indeed, lag time and velocity were not normalized in all samples with rivaroxaban levels higher than $200 \mathrm{ng} / \mathrm{mL}$. This was expected because, unlike true "antidotes", PCCs cannot inactivate FXa inhibitors.

The major limitation of our work is its pre-clinical in vitro design; no attempt was done to extend these results to clinical situations. Although PCC composition should meet precise criteria established by the European 


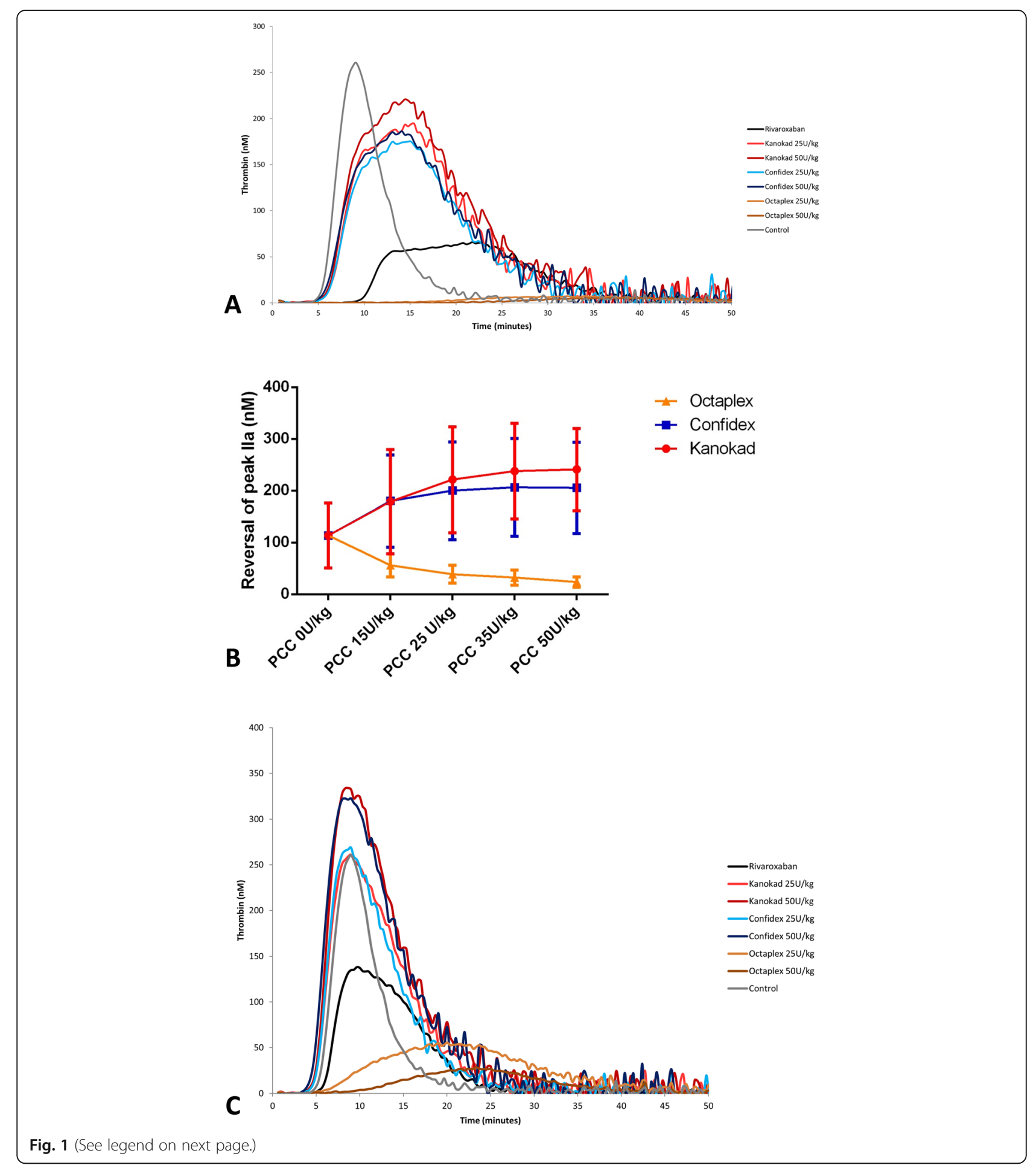


(See figure on previous page.)

Fig. 1 A. Typical "camel-back"-shaped thrombin generation curve obtained in patients treated with rivaroxaban (black curve). In this sample, rivaroxaban concentration was $89 \mathrm{ng} / \mathrm{mL}$. In this sample, lag time was prolonged, and peak height and endogenous thrombin potential (ETP) were decreased compared with the normal control (grey). Lag time and peak height were restored after addition of the [4-]factor PCCs Kanokad ${ }^{\circledR}$ or Confidex ${ }^{\oplus}$ at the doses of 25 and $50 \mathrm{U} / \mathrm{kg}\left(0.625\right.$ and $1.25 \mathrm{U} / \mathrm{mL}$ respectively). Octaplex ${ }^{\circledast}$ did not have any effect in vitro, probably because of the high heparin content in this preparation. ETP was partially restored after PCC addition. Figure 1B. Dose-dependent changes of the in vitro thrombin generation peak in the presence of increasing concentrations of the indicated 4-factor PCCs. The four concentrations (0-15 - 25 - 35 and $50 \mathrm{U} \cdot \mathrm{kg}^{-1}$ ) correspond to the final concentrations of $0-0.375-0.625-0.875$ and $1.25 \mathrm{U} \cdot \mathrm{mL}^{-1}$ in plasma samples containing rivaroxaban. Figure 1C. Thrombin generation curve of a sample with low rivaroxaban concentration ( $48 \mathrm{ng} / \mathrm{mL}$ ). Before PCC addition, lag time was slightly prolonged, peak height was decreased, and ETP was normal compared with control. Lag time and peak height were restored after addition of the 4-factor PCCs Kanokad ${ }^{\oplus}$ and Confidex ${ }^{\oplus}$ at the dose of $25 \mathrm{U}^{.} \mathrm{kg}^{-1}(0.625 \mathrm{U} / \mathrm{mL})$. In the rivaroxaban-containing sample, peak height and ETP were higher than in control after spiking with PCC $50 \mathrm{U} \cdot \mathrm{kg}^{-1}(1.25 \mathrm{U} / \mathrm{mL})$

Pharmacopoeia, they differ in terms of inhibitor content (such as antithrombin), and concentration of heparin and of some coagulation factors. Moreover, batch-tobatch variations may be observed for the same brand. All these variations, associated with the in vivo pharmacokinetic characteristics of these complex molecules, make the extrapolation of in vitro results to clinical situations very difficult. Another limitation of our study was that blood samples were collected at random times and not at peak levels. Therefore, PCC effect might have been overestimated.

In agreement with our pre-clinical data, two recent clinical studies showed that in clinical situations, half of the patients treated with PCCs for urgent rivaroxaban or apixaban reversal received the dose of $25 \mathrm{U}^{-\mathrm{kg}^{-1}}$ (although $50 \mathrm{U} \cdot \mathrm{kg}^{-1}$ is the recommended dose), and had a good clinical outcome $[15,16]$. Our in vitro finding and these clinical results indicate that 4-factor PCCs at the dose of $25 \mathrm{U} \cdot \mathrm{kg}^{-1}$ may be sufficient to reverse rivaroxaban anticoagulant effect. Moreover, the high peak height and ETP values observed in samples containing low concentration of rivaroxaban and PCCs $50 \mathrm{U} \cdot \mathrm{kg}^{-1}$ suggest that in some patients, high-dose PCCs might increase the risk of thrombosis. Although specific reversal agents for anti-Xa inhibitors are available, PCCs still have a role in centres without access to specific antidotes and also when the used anticoagulant agent is unknown. Large, prospective clinical studies are needed to determine the optimal dose of 4-factor PCCs for reversal of factor-Xa inhibitor activity.

\section{Acknowledgements}

This study was supported by CSL Behring France. CSL Behring did not interfere with the study design, the interpretation of the results, and the writing process.

Ethical Approval and Consent to participate.

The study was approved by the local ethical committee.

\section{Authors' contributions}

LGQ performed TGA experiments, HDC and CG included patients, YJ performed routine coagulation measurements, YD designed the study, analysed the results and wrote the manuscript. All authors critically revised the manuscript.

\section{Authors' information}

NA

\section{Funding \\ CSL Behring.}

\section{Availability of data and materials}

Yes

\section{Consent for publication}

Yes

\section{Competing interests}

All authors declare no competing financial interests.

\section{Author details}

${ }^{1}$ GEMMAT Groupe d'Etude Multidisciplinaire en Maladies Thrombotiques, Lyon, France. ${ }^{2}$ Service de Medecine Interne, Medecine Vasculaire, Hopital Edouard Herriot, Lyon, France. ${ }^{3}$ Service de Medecine Interne, Medecine Vasculaire, Centre Hospitalier Lyon Sud, Lyon, France. ${ }^{4}$ Laboratoire d'Hematologie, Groupement Hospitalier Est, Hospices Civils de Lyon, Lyon, France. ${ }^{5}$ Unite d'Hemostase Clinique, Hopital Cardiologique Louis Pradel, 28, avenue Doyen J. Lepine, F-69500 Bron, Lyon, France.

Received: 27 December 2019 Accepted: 7 July 2020

Published online: 24 August 2020

\section{References}

1. Ruff C, Giugliano R, Antman E. Management of bleeding with nonvitamin K antagonists oral anticoagulants in the era of specific reversal agents. Circulation. 2016;134:248-61.

2. Myers B, Webster A. Heavy menstrual bleeding on rivaroxaban - comparison with Apixaban. Br J Haematol. 2017;176:833-5.

3. Connolly, S.J., Milling Jr, T.J., Eikelboom, J.W., Gibson, C.M., Curnutte, J.T., Gold, A., Bronson, M.D., Lu, G., Conley, P.B., Verhamme, P., Schmidt, J., Middeldorp, S., Cohen, A.T., Beyer- Westendorf, J., Albaladejo, P., LopezSendon, J., Goodman, S., Leeds, J., Wiens, B.L., Siegal, D.M., Zotova, E., Meeks, B., Nakamya, J., Lim,W.T. \& Crowther, M. (2016). Andexanet Alfa for acute major bleeding associated with factor Xa inhibitors. N Engl J Med, 375, 1131-1141.

4. Steffel J, Verhamme P, Potpara TS, Albaladejo P, Antz M, Desteghe L, et al. The 2018 European heart Rythm association practical guide on the use of the non-vitamin $\mathrm{K}$ antagonist oral anticoagulants in patients with atrial fibrillation. Eur Heart J. 2018;39:1330-93.

5. Deepa R. J. Arachchillage, Sharon Alavian, Jessica Griffin, Kamala Gurung,Richard Szydlo, Nilanthi Karawitage and Mike Laffan Efficacy and safety of prothrombin complex concentrate in patients treated with rivaroxaban or apixaban compared to warfarin presenting with major bleeding British Journal of Haematology, 2019, 184, 808-816.

6. Berger K, Santibanez M, Lin L, Lesch CA. A low-dose 4F-PCC protocol for DOAC-associated intracranial hemorrhage. J Intensive Care Med. 2019 Apr; 14:885066619840992. 
7. Dager WE, Roberts AJ, Nishijima DK. Effect of low and moderate dose FEIBA to reverse major bleeding in patients on direct oral anticoagulants. Thromb Res. 2019;173:71-6.

8. Marlu R, Hodaj E, Paris A, Albaladejo P, Cracowski JL, Pernod G. Effect of nonspecific reversal agents on anticoagulant activity of dabigatran and rivaroxaban: a randomised crossover ex vivo study in healthy volunteers. Thromb Haemost. 2012;108:217-24.

9. Hoffman M, Goldstein JN, Levy JH. The impact of prothrombin complex concentrates when treating DOAC-associated bleeding: a review. Int J Emerg Med. 2018 Dec 3;11(1):55.

10. Dzik WH. Reversal of oral factor Xa inhibitors by prothrombin complex concentrates: a re-appraisal. J Thromb Haemost. 2015;13(Suppl 1):S187-94.

11. Brummel-Ziedins KE, Wolberg AS. Global Assays of Hemostasis. Curr Opin Hematol. 2014;21:395-403.

12. Dargaud Y, Desmurs-Clavel H, Marin S, Bordet JC, Poplavsky JL, Negrier C. Comparison of the capacities of two prothrombin complex concentrates to restore thrombin generation in plasma from orally anticoagulated patients: an in vitro study. J Thromb Haemost. 2008 Jun;6(6):962-8.

13. Makhoul S, Panova-Noeva M, Regnault V, Ruf W, Wenzel P, Lagrange J. Rivaroxaban Effects Illustrate the Underestimated Importance of Activated Platelets in ThrombinGeneration Assessed by Calibrated Automated Thrombography. J Clin Med. 2019 Nov 15;8(11). pii: E1990.

14. Albaladejo P, Bonhomme F, Blais N, Collet JP, Faraoni D, Fontana P, Godier A, Llau J, Longrois D, Marret E, Mismetti P, Rosencher N, Roullet S, Samama CM, Schved JF, Sié P, Steib A, Susen S; French Working Group on Perioperative Hemostasis (GIHP). Management of direct oral anticoagulants in patients undergoing elective surgeries and invasive procedures: Updated guidelines from the French Working Group on Perioperative Hemostasis (GIHP) - September 2015. Anaesth Crit care pain med. 2017 Feb;36(1):73-76.

15. Eerenberg ES, Kamphuisen PW, Sijpkens MK, Meijers JC, Buller HR, Levi M. Reversal of rivaroxaban and dabigatran by prothrombin complex concentrate: a randomized, placebo-controlled, crossover study in healthy subjects. Circulation. 2011;124:1573-9.

16. Tao J, Bukanova EN, Akhtar S. Safety of 4-factor prothrombin complex concentrate (4F-PCC) for emergent reversal of factor Xa inhibitors. J Intensive Care. 2018 Jun 14;6:34.

\section{Publisher's Note}

Springer Nature remains neutral with regard to jurisdictional claims in published maps and institutional affiliations.

Ready to submit your research? Choose BMC and benefit from:

- fast, convenient online submission

- thorough peer review by experienced researchers in your field

- rapid publication on acceptance

- support for research data, including large and complex data types

- gold Open Access which fosters wider collaboration and increased citations

- maximum visibility for your research: over $100 \mathrm{M}$ website views per year

At $\mathrm{BMC}$, research is always in progress.

Learn more biomedcentral.com/submissions 